\title{
Article \\ Effects of Climatic Change on the Potential Distribution of Lycoriella Species (Diptera: Sciaridae) of Economic Importance
}

\author{
Roberta Marques ${ }^{1,2,3} \mathbb{D}^{\mathbb{D}}$, Juliano Lessa Pinto Duarte ${ }^{4, *}$, Adriane da Fonseca Duarte ${ }^{4} \mathbb{D}$, Rodrigo Ferreira Krüger ${ }^{2}$, \\ Uemmerson Silva da Cunha ${ }^{4}$, Luis Osorio-Olvera ${ }^{5}$ D, Rusby G. Contreras-Díaz ${ }^{6,7}$ (D) \\ and Daniel Jiménez-García ${ }^{3, * \text { iD }}$
}

check for updates

Citation: Marques, R.; Duarte, J.L.P.; Duarte, A.d.F.; Krüger, R.F.; Silva da Cunha, U.; Osorio-Olvera, L.; Contreras-Díaz, R.G.; Jiménez-García, D. Effects of Climatic Change on the Potential Distribution of Lycoriella Species (Diptera: Sciaridae) of Economic Importance. Insects 2021, 12, 831. https://doi.org/10.3390/ insects12090831

Academic Editor: Brian T. Forschler

Received: 9 July 2021

Accepted: 7 September 2021

Published: 15 September 2021

Publisher's Note: MDPI stays neutral with regard to jurisdictional claims in published maps and institutional affiliations.

Copyright: (c) 2021 by the authors. Licensee MDPI, Basel, Switzerland. This article is an open access article distributed under the terms and conditions of the Creative Commons Attribution (CC BY) license (https:// creativecommons.org/licenses/by/ $4.0 /)$.
1 Departamento de Saúde Coletiva, Faculdade de Ciências Médicas, Universidade Estadual de Campinas, Campinas 13083-970, Brazil; roberta.marques@viep.com.mx

2 Laboratório de Ecologia de Parasitos e Vetores, Departamento de Microbiologia e Parasitologia, Universidade Federal de Pelotas, Pelotas 96010-610, Brazil; rfkruger@gmail.com

3 Laboratorio de Biodiversidad, Centro de Agroecología y Ambiente, Instituto de Ciencias de la Benemérita, Universidad Autónoma de Puebla, Puebla 72410, Mexico

4 Departamento de Fitossanidade, Faculdade de Agronomia Eliseu Maciel, Campus Capão do Leão, Universidade Federal de Pelotas-UFPel, Capão do Leão 96160-000, Brazil; adriane.faem@hotmail.com (A.d.F.D.); uscunha@yahoo.com.br (U.S.d.C.)

5 Departamento de Ecología de la Biodiversidad, Instituto de Ecología, Universidad Nacional Autónoma de México, Ciudad de México 04510, Mexico; luis.osorio@iecologia.unam.mx

6 Departamento de Matemáticas, Facultad de Ciencias, Universidad Nacional Autónoma de México, Ciudad de México 04510, Mexico; rusby.contreras.diaz@gmail.com

7 Posgrado en Ciencias Biológicas, Unidad de Posgrado, Universidad Nacional Autónoma de México, Ciudad de México 04510, Mexico

* Correspondence: duartejlp@gmail.com (J.L.P.D.); daniel.jimenez@correo.buap.mx (D.J.-G.)

Simple Summary: Here, we describe climate change effects on biodiversity, mainly in pest species related to greenhouse production. We used statistical and theoretical methods to describe crops' vulnerability under worldwide climate change. Some insects (flies) generate economic damage in mushroom, strawberry, and nursery production. We determined potential risk areas for the invasion of three fly species under different climate change scenarios in 2050. Range expansion was determined in the Northern Hemisphere; however, some regions in South America, Africa, and Australia had increases and potentially invasive areas. Our results provide information for farmers, researchers, and politicians for decision-making around production to reduce possible damage caused by pests.

Abstract: Lycoriella species (Sciaridae) are responsible for significant economic losses in greenhouse production (e.g., mushrooms, strawberries, and nurseries). The current distributions of species in the genus are restricted to cold-climate countries. Three species of Lycoriella are of particular economic concern in view of their ability to invade areas in countries across the Northern Hemisphere. We used ecological niche models to determine the potential for range expansion under future climate change scenarios (RCP 4.5 and RCP 8.5) in the distribution of these three species of Lycoriella. Stable environmental suitability under climate change was a dominant theme in these species; however, potential range increases were noted in key countries (e.g., USA, Brazil, and China). Our results illustrate the potential for range expansion in these species in the Southern Hemisphere, including some of the highest greenhouse production areas in the world.

Keywords: greenhouse; environmental suitability; mushroom pest; black fungus gnats

\section{Introduction}

Sciaridae (Insecta, Diptera), known as black fungus gnats, comprise more than 2600 species worldwide, most of which are harmless to human activities [1]. Although most of the species have phyto-saprophagous larvae, 10 known species have larvae that 
may feed on living tissue, thus damaging roots or mining stems and leaves of economically important crops and ornamental plants, which can lead to significant economic losses [2-5].

Mushroom crops can be severely affected by sciarids. Sciarid larvae can feed on the developing mycelium inside the substrate and destroy sporophore primordia. Mature mushrooms may also be damaged by larvae tunneling into the tissue, which leads to product depreciation. Severe larval infestations may even destroy the sporophores, causing severe economic losses to producers [6].

Since 1978, worldwide production of cultivated edible fungi has increased around 30-fold and is expected to increase further in coming years [7]. Mushrooms represented a global market of USD 63 B in 2013 [8]. According to the USDA, the value of mushroom sales for 2019-2020 in the USA was USD 1.15 B, up 3\% from the previous season [9]. Among the mushrooms produced, Agaricus bisporus is the most important, according to the Economics, Statistics and Market Information System. In 2020-2021, the area under production consisted of $12,470 \mathrm{~m}^{2}, 56.5 \%$ of which is in the state Pennsylvania [9].

The mushroom industry has suffered major economic losses due to sciarid larvae in Australia, USA, Russia, United Kingdom, and South Korea [10,11]. Three sciarid species of the genus Lycoriella Frey, 1942 (L. agraria, L. ingenua, and L. sativae) are particularly harmful to cultivated mushroom crops, and are considered to rank among the most important pests of cultivated mushrooms throughout the world $[4,10]$. In countries like the United States and England, L. ingenua and L. sativae are the most serious pests in mushroom crops [12], as well in Europe [10]. In Korea, L. ingenua is considered to be the most economically important [11]. Given their small size, sciarid larvae can be inadvertently transported to new areas by human activities. Infested potting mix, soilless media, commercial plant substrate, and rooted plant plugs have been shown to act as pathways for sciarid movement [13]. From 1950 onwards, globalization promoted the transport of these invasive species [14]. In this sense, studies of their ecology, environmental requirements, and climatic change impacts for the establishment of invasive populations are needed.

Ecological niche modeling (ENM) is used to evaluate relationships between environmental conditions and species' abundance and occurrence [15]. Understanding the potential distributions of species represents an important opportunity for pest control and mitigation of possible invaders e.g., [16-18]. Considering that the three Lycoriella species are economically important and are invasive species $[10,19]$, niche modeling allows researchers to identify areas not currently occupied by them; if dispersal is possible or facilitated, these areas can be invaded and populations established in these regions [15]. For these reasons, we used ENM to identify new regions of potential risk of invasion by three Lycoriella species with pest status in mushroom production, under current and future climate conditions (2050) for two greenhouse gas emissions scenarios.

\section{Materials and Methods}

\subsection{Occurrence Data}

Occurrence data for Lycoriella species were obtained from published papers available in bibliographic databases (Google Scholar, Web of Science, Scopus; Supplementary Information), and from SpeciesLink (http:/ /splink.cria.org.br/ (accessed on 13 January 2020)) and GBIF (http: / / www.gbif.org (accessed on 15 November 2020)). We gathered all data from 1950-2018 for synonyms [3] including L. agraria [20] and its synonym Sciara multiseta [21], L. ingenua [22] and its synonym S. pauciseta [23] and L. sativae [24], and its synonyms L. auripila [25] and L. castanescens [26]. Occurrence data lacking geographic coordinates were georeferenced in Google Earth (2015; https: / / earth.google.com/web/ (accessed on 15 February 2020)). We excluded records lacking the exact location or with high geographic uncertainty (e.g., name of the country as a collection site).

We assembled the occurrence data for each Lycoriella species at world level, and performed a geographic spatial thinning such that no thick points were closer than $5 \mathrm{~km}$ using the spThin R package [27]. As such, we used 43 L. agraria occurrences, 118 L. ingenua 
occurrences, and 136 L. sativae occurrences. Finally, the data were split randomly into two subsets: 50\% for model training and 50\% for model testing (Figures S1-S3).

\subsection{Environmental Variables}

The bioclimatic variables used here to summarize climatic variation were from WorldClim version 1.4 [28]; we excluded four variables (bio 8, bio 9, bio 18, bio 19) that present spatial artefacts [29]. We summarized future conditions via 22 general circulation models (GCMs, Table S1) for 2050 available from Climate Change, Agriculture and Food Security [30]. Two scenarios for greenhouse gas emissions (RCP 4.5 and RCP 8.5) were used to explore variation in possible trajectories for future emissions. The climate variables were used at a spatial resolution of $2.5 \mathrm{~min}\left(\sim 5 \mathrm{~km}^{2}\right)$. We used Pearson's correlations across each of the calibration areas for each species, removing one from each pair of variables with a correlation $\geq 0.80$. The remaining non-correlated variables were grouped into all possible sets of $\geq 2$ variables for testing [31] (Table 1).

Table 1. Best models selected and evaluated based on statistical significance (partial ROC), performance (omission rates: $\mathrm{OR}$ ), and complexity (AICc). This model was calibrated and projected using the environmental variables shown in Table 2.

\begin{tabular}{|c|c|c|c|c|c|c|c|}
\hline Lycoriella Species & $\begin{array}{c}\text { Mean AUC } \\
\text { Ratio }\end{array}$ & $\begin{array}{c}\mathrm{pROC} \\
p \text { Value }\end{array}$ & $\begin{array}{l}\text { Omission } \\
\text { Rate at } 5 \%\end{array}$ & $\mathrm{AICc}$ & Delta AICc & $\begin{array}{c}\text { Reg. } \\
\text { Multiplier }\end{array}$ & $\begin{array}{l}\text { Feature } \\
\text { Classes }\end{array}$ \\
\hline \multirow{7}{*}{$\begin{array}{c}\text { L. agraria } \\
1170 \text { models }\end{array}$} & 1.000 & 0 & 0.04 & 829.260 & 0.000 & 1 & lqpt \\
\hline & 1.049 & 0 & 0.04 & 830.493 & 1.232 & 1 & lqpt \\
\hline & 1.000 & 0 & 0 & 830.664 & 1.401 & 3 & lqpth \\
\hline & 1.000 & 0 & 0 & 830.667 & 1.407 & 3 & lqpth \\
\hline & 1.000 & 0 & 0 & 830.667 & 1.407 & 3 & lqpth \\
\hline & 1.000 & 0 & 0.04 & 831.205 & 1.945 & 1 & lqpt \\
\hline & 1.000 & 00 & 0.04 & 831.208 & 1.948 & 1 & lqpt \\
\hline \multirow{4}{*}{$\begin{array}{l}\text { L. ingenua } \\
15,561 \text { models }\end{array}$} & 1.036 & 0 & 0.01 & 2425.36 & 0 & 3 & 1 \\
\hline & 1.035 & 0 & 0.03 & 2425.366 & 0.005 & 0.1 & 1 \\
\hline & 1.036 & 0 & 0.03 & 2425.366 & 0.005 & 0.3 & 1 \\
\hline & 1.036 & 0 & 0.03 & 2425.366 & 0.005 & 0.5 & 1 \\
\hline \multirow{9}{*}{$\begin{array}{c}\text { L. sativae } \\
5400 \text { models }\end{array}$} & 1.035 & 0 & 0.03 & 2425.366 & 0.005 & 0.7 & 1 \\
\hline & 1.035 & 0 & 0.03 & 2425.366 & 0.005 & 1 & 1 \\
\hline & 1.052 & 0 & 0.031 & 2766.137 & 0 & 3 & 1 \\
\hline & 1.047 & 0 & 0.046 & 2766.874 & 0.736 & 0.1 & 1 \\
\hline & 1.044 & 0 & 0.046 & 2766.874 & 0.736 & 0.3 & 1 \\
\hline & 1.046 & 0 & 0.046 & 2766.874 & 0.736 & 0.5 & 1 \\
\hline & 1.045 & 0 & 0.031 & 2766.874 & 0.736 & 0.7 & 1 \\
\hline & 1.043 & 0 & 0.015 & 2766.874 & 0.736 & 1 & 1 \\
\hline & 1.000 & 0 & 0 & 2767.922 & 1.784 & 3 & pth \\
\hline
\end{tabular}

Table 2. Models and variables that were relatively uncorrelated (Pearson's correlation $\leq 0.8$ ) for Lycoriella species. The models were built and tested used 26 variables sets for L. agraria, 247 variables sets for L. ingenua, and 120 variables sets for L. sativae.

\begin{tabular}{ccc}
\hline Species & Uncorrelated Variables & Variable Contribution (\%) \\
\hline & Mean diurnal range & 4.60 \\
& Mean temperature of warmest quarter & 48.67 \\
L. agraria & Mean temperature of coldest quarter & 0.00 \\
& Precipitation of wettest quarter & 22.67 \\
& Precipitation of driest quarter & 24.05 \\
\hline \multirow{2}{*}{ L. ingenua } & Temperature seasonality & 28.90 \\
& Maximum temperature of warmest month & 0.00 \\
& Mean temperature of coldest quarter & 49.80 \\
\hline
\end{tabular}


Table 2. Cont.

\begin{tabular}{ccc}
\hline Species & Uncorrelated Variables & Variable Contribution (\%) \\
\hline & Mean diurnal range & 38.26 \\
& Maximum temperature of warmest month & 29.44 \\
& Temperature annual range & 0.00 \\
L. sativae & Mean temperature of coldest quarter & 7.89 \\
& Annual precipitation & 8.18 \\
& Precipitation of wettest quarter & 5.77 \\
& Precipitation of driest quarter & 10.41 \\
\hline
\end{tabular}

\subsection{Model Calibration and Evaluation}

We used correlative models and the relationship between occurrence data and environmental variables to predict potential distribution based on ecological niche models (ENM). We calibrated candidate models in Maxent 3.4.1 [32], and model selection was achieved using the kuenm $R$ package [33]. We assessed all potential combinations of linear $(\mathrm{l})$, quadratic $(\mathrm{q})$, product $(\mathrm{p})$, threshold $(\mathrm{t})$, and hinge $(\mathrm{h})$ feature types, in tandem with 9 regularization multiplier values $(0.1,0.3,0.5,0.7,1,3,5,7$ and 10), and the 26,247 , and 120 environmental data sets described above, for L. agraria, L. ingenua, and L. sativae, respectively. Therefore, we explored 1170 candidate models for L. agraria, 15,561 for L. ingenua, and 5400 for L. sativae (Table 1). We evaluated the significance, performance, and complexity of each candidate model to choose the optimal parameter settings, as follows. Significance testing was via partial receiver operating characteristic (pROC) tests [34]; values of partial ROC were calculated based on a maximum acceptable omission error rate of $E=0.05$. Omission rates were determined using a random $50 \%$ of the occurrence data, and model predictions were binarized via a modified least training presence thresholding approach $(E=0.05)$. Finally, we evaluated model complexity using the Akaike information criterion with correction for small sample size (AICc), following Warren and Seifert (2011) [35]. All modeling processes were included in the kuenm $\mathrm{R}$ package [33].

We used a hypothesis of the accessible area (M) for each species to calibrate our models [36,37], using buffers of $50 \mathrm{~km}$ around occurrence data points that remained after spatial thinning. Final models were taken as the median of the 10 replicates for the best models and were projected worldwide. Model summaries were generated from thresholded median model projections (Figure 1) using the $E=0.05$ value. We used the kuenm package [33] for these final steps as well. For each future-climate scenario (RCP 4.5 and RCP 8.5), we transferred the models and evaluated extrapolation conditions through MOP analysis [38], using the ntbox $R$ package [39].

We summarized the projections of the models as medians of the replicate models using a modified least presence threshold value of $E=0.05$. Binary maps for future conditions were used to determine uncertainty in terms of disagreement among predictions from the different GCMs (Figure 1) and median summarize for both scenarios (Figures S4-S6). We summed the maps and used the overlap between the present and future potential distribution areas to determine the prediction stability and range increase for each species in geographic areas with low extrapolation risk based on MOP analysis (Figures S7-S9). 

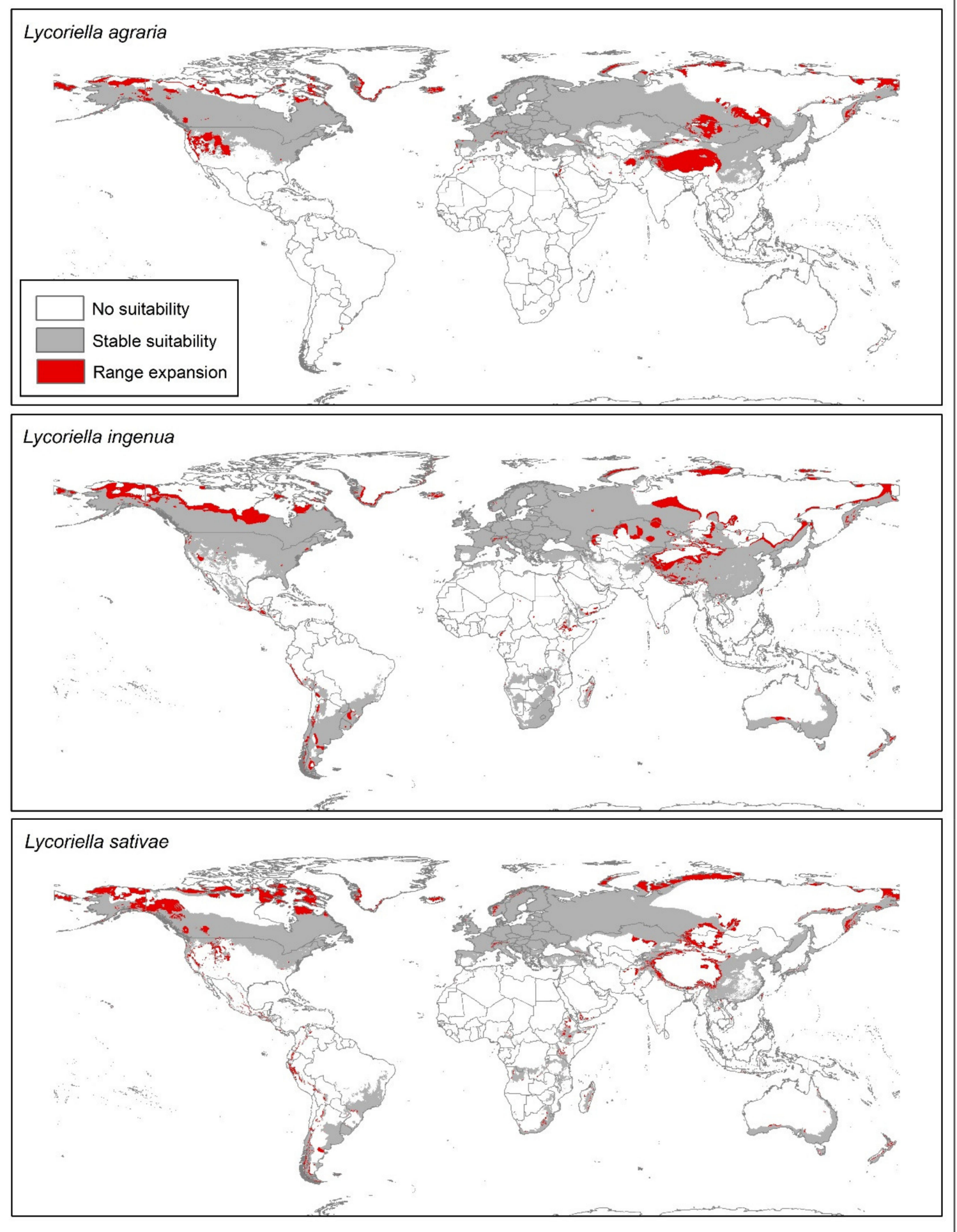

Figure 1. Potential distribution of three Lycoriella species under present and future climate conditions under two emissions scenarios (RCP 4.5 and RCP 8.5). Models show potential for range expansion worldwide in areas with low extrapolation risk.

\section{Results}

We created and evaluated 22,131 candidate models for the three Lycoriella species at the worldwide level, (Table 1). For L. agraria, of 1170 candidate models, 669 were significant $(p<0.05)$ and 575 had omission rates below 5\%; of the significant, low-omission models, 7 were selected according to low complexity (AICc; Table 1). Of 15,561 candidate models 
for L. ingenua, 6898 were significant and 6789 models had omission rates below 5\%; we selected 6 models based on complexity. Finally, we generated 5400 candidate models for L. sativae, of which 1323 were significant and 1061 had omission rates below 5\%. We selected 7 models according to AIC criteria (Table 1).

Nine variables were identified as key in our ENMs (Table 2). In general, Lycoriella species showed relationships with seasonality in temperature and precipitation, and with variables related to cold temperatures and wet seasons (Table 2), with variable contributions ranging from 4.6 to $49.8 \%$. The maximum number of variables for best models was in L. sativae, including large differences in variable contribution (Table 2).

Currently, suitable areas for Lycoriella species include much of the Northern Hemisphere, except for parts of Greenland, Russia, and northern China. Several areas in the Southern Hemisphere would also be suitable for L. ingenua and L. sativae: South America, southern Africa, and Australia (Figures 1 and 2). The model for L. agraria indicated high suitability in parts of North America, except Mexico (Figures 1 and 2), as well as much of Eurasia except for Russia, the Indian Subcontinent, and Southeast Asia. Much of the Americas were indicated as suitable areas for L. ingenua, except for parts of Canada, Alaska, Central America, and northern South America. Lycoriella sativae showed high suitability in the Americas, except in the western United States, northern Canada, central Mexico, and parts of South America (e.g., northern Brazil, Pacific Coast). Eastern and southern Asia were not suitable for this species, nor were much of Australia, North Africa, or parts of central and southern Africa.

Stable, suitable conditions for the three Lycoriella species were the dominant pattern in comparisons of current and future potential distributions (Figure 1, Figures S4-S6). Potential range expansion for the three species was noted in North America and Southeast Asia (Figure 1, Figures S4-S6). Range reductions were detected in each species but were covered (less than $\sim 78,000 \mathrm{~km}^{2}$ ) in disaggregated pixels; however, the main areas of reduction were in Asia (southern China and Mongolia). The broadest range expansions for L. agraria were anticipated in Asia (China, Russia, and Mongolia). In contrast, for L. ingenua, our results did not show a homogeneous pattern of potential range expansion; however, we noted increases in suitability in the Americas, Africa, Asia, Europe, and Australia. The biggest changes in the potential distribution of L. sativae were in North America and western parts of South America (Figure 1). New potential range areas were also identified in Alaska and Canada (Figure 1). A potential overlap in the range of Lycoriella agraria and L. sativae was indicated in the western United States (Nevada, Arizona, Idaho, Wyoming, and Colorado) (Figures 1 and 2). Potential range overlaps for L. agraria with L. ingenua, and L. ingenua with L. sativae were noted in central and western China (Qinghai, Xizang, and Xinjiang), central Kazakhstan, northern and northwestern Mongolia, northern Siberia, and the border regions between China and Mongolia (Figures 1 and 2). 

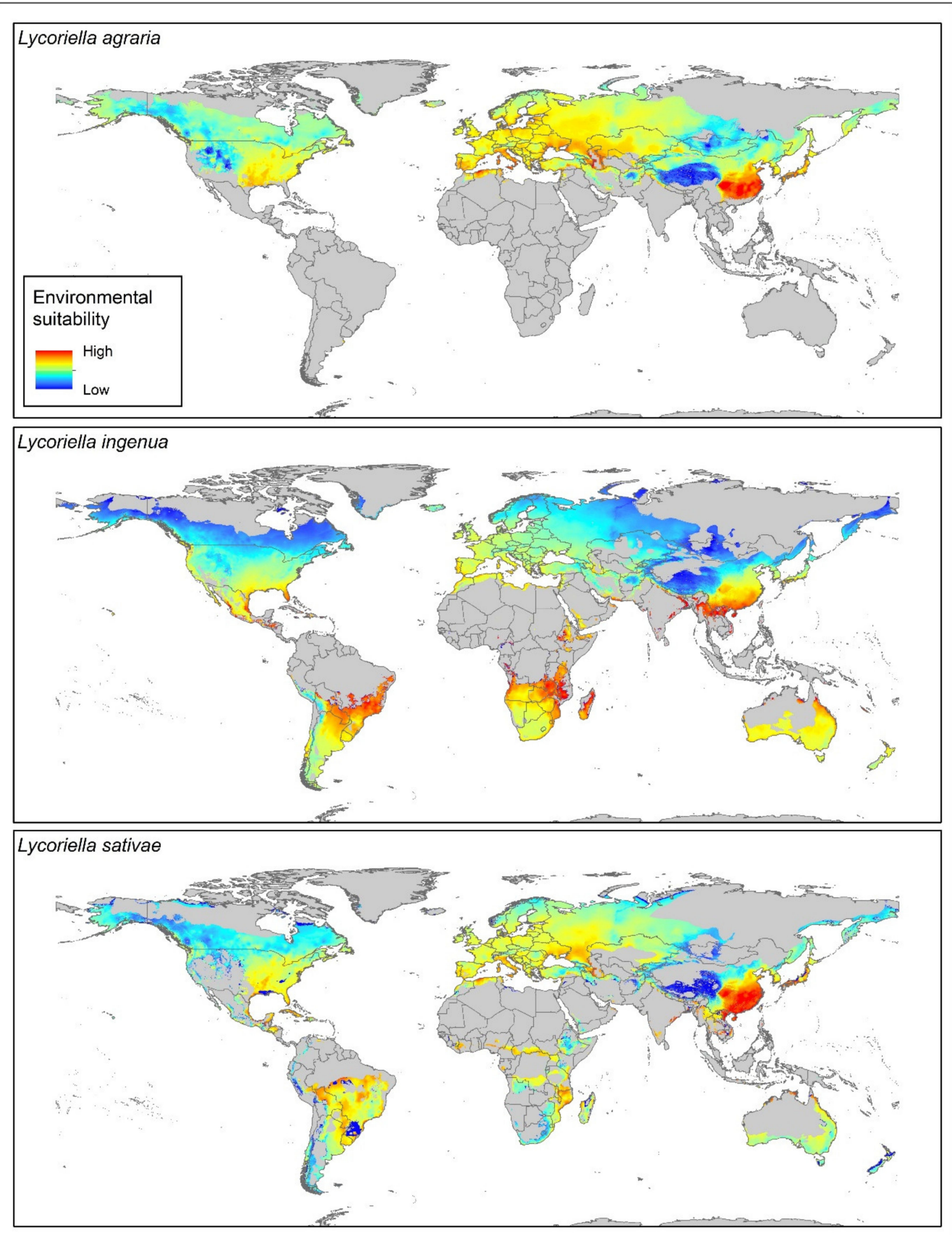

Figure 2. Environmental suitability for three Lycoriella species under current climate conditions worldwide.

\section{Discussion}

It is generally accepted that environmental changes will modify species' geographic distributions worldwide [40]. Understanding how these changes will influence species distributions is particularly key for economically important species. Sciaridae species occur almost worldwide [10], and include important pests of mushroom crops [3], mainly in the genera Bradysia and Lycoriella [6]. 
Lycoriella includes the most threatening pests (e.g., our three species), and causes major damage to mushroom production [4]. In Korea, the most economically critical oyster mushroom pest among the six mushroom fly species is L. ingenua [11]. Usually, L. sativae is the most abundant in fields, but it is much less damaging than L. ingenua in mushroom culture [3].

How climate change will affect the geographic distributions of economically important sciarid species remains an open question. According to Sawangproh et al. [41], ambient temperature can affect not only the survival and larval development of sciarid flies, but also their feeding activity. As such, damage in mushroom crops or nurseries will be influenced by lower or higher temperatures. Apart from regional species checklists, little is known about the factors that drive these species' distributions, so consequently little is known about the impacts of climate change on the future distributions of these species. These insects are easily transported by human activities, and once they reach a suitable environment, they can build up their population, which can lead to major economic losses and establish populations in mushroom production areas.

Few studies have investigated the presence of sciarids in the Afrotropical region. Chidziya et al. [42] assessed L. ingenua (as L. mali) to be the most damaging mushroom fly in Zimbabwe, but provided no occurrence records for the species. Katumanyane et al. [43] reported for the first time the presence of both L. ingenua and L. sativae in South Africa. Our model predicted suitable environmental conditions for these species in the southern portion of the African continent, including the above-mentioned countries (Figures 1 and 2), though no points from either country were included in the dataset used in model calibration.

The dominant and most serious pest species in mushroom crops in North America is L. ingenua [12]. Our results show that for the USA, for example, the current environmental suitability for this species is moderate for the entire West Coast and most of the southeastern part of the country, including most of the East Coast (Figure 1, Figure S5). Most of California presents high environmental suitability for the species, which is particularly relevant because California ranks second in the number of mushroom growers in the country, after Pennsylvania [9].

Pennsylvania itself currently has moderate environmental suitability (Figure 2), and our model predicts stable environmental suitability for the state under future scenarios (Figure S5). These results should be taken into consideration, since they could lead to major economic losses to mushroom producers, considering that about $66 \%$ of all US mushroom growers are located in this state [9].

In South America, on the other hand, mushroom production is still incipient. It plays a growing social role as it provides a different source of income for producers at the local level. Brazil is the most outstanding case in South America, although efforts to cultivate mushrooms are beginning in other countries [44].

So far, no official record of species of Lycoriella exists for Brazil. Our model showed high environmental suitability in most of southern and southwestern Brazil for L. ingenua and L. sativae (Figure 2). As such, once these species are introduced into the country, they will likely have the ability to establish stable populations, a fact that must be regarded with care because most Brazilian mushroom production is concentrated in the southern and southwestern states. The introduction of Lycoriella species to the country would pose an extra threat to Brazilian mushroom growers, who already face problems with other sciarid and scatopsid species $[45,46]$.

The genus Lycoriella significantly reduces mushroom production inside greenhouses; these species also may impact other agricultural species (e.g., strawberry, nursery plants [6,47,48]. Our results show areas around the world with suitable conditions for these flies (Figure 2). We are particularly concerned about greenhouse availability, although we did not incorporate possible competition with other species into our models. However, Lycoriella species show very broad ecological niches with high invasive potential, from Brazil to Alaska. We suggest that experimental physiological studies that address the fundamental niche of 
these species more directly will be an important next step in protecting food production in greenhouses, and to characterize areas with environmental conditions that characterize the physiological limits of the development of Lycoriella populations.

Supplementary Materials: The following are available online at https://www.mdpi.com/article/ 10.3390/insects12090831/s1, Figure S1: Known distribution areas of Lycoriella agraria, Figure S2: Known distribution areas of Lycoriella ingenua, Figure S3: Known distribution areas of Lycoriella sativae, Figure S4: Projections of environmental suitability for Lycoriella agraria in current and future scenarios, Figure S5: Projections of environmental suitability for Lycoriella ingenua in current and future scenarios, Figure S6: Projections of environmental suitability for Lycoriella sativae in current and future scenarios, Figure S7: MOP analysis of extrapolation risk from the calibration area under projection current and future conditions for Lycoriella agraria, Figure S8: MOP analysis of extrapolation risk from the calibration area under projection current and future conditions for Lycoriella ingenua, Figure S9: MOP analysis of extrapolation risk from the calibration area under projection current and future conditions for Lycoriella sativae, Table S1: General circulation models used in ecological niche model projections in RCP 4.5 and RCP 8.5 for 2050, Table S2; Bibliographic references used for occurrences data of Lycoriella species.

Author Contributions: R.M.: Conceptualization, Analysis, Writing Original Draft, Supervision, Project Administration, Analysis and Construction. J.L.P.D.: Conceptualization, Data Curation, Writing Original Draft, Discussion. R.F.K.: Conceptualization, Discussion. A.d.F.D.: Writing Original Draft, Data Curation, Discussion. U.S.d.C.: Writing Original Draft. R.G.C.-D.: software and revision. L.O.-O.: software and revision. D.J.-G.: Conceptualization, Analysis, Writing Original Draft, Discussion. All authors have read and agreed to the published version of the manuscript.

Funding: This research was funded by Coordenação de Aperfeiçoamento de Pessoal de Nível Superior, grants numbers $47 / 2017 ; 88882.306693 / 2018-01 ; 88882.182253 / 2018-01$. DJG was funded by Fulbright Visiting Scholar Program (Senior Scholar) and Vicerrectoría de Investigación y Estudios de Posgrado-BUAP.

Institutional Review Board Statement: Not applicable.

Data Availability Statement: The data presented in this study are available in Supplementary Materials.

Acknowledgments: We thank A. Townsend Peterson for comments and suggestions. We thank the Coordenação de Aperfeiçoamento de Pessoal de Nível Superior (CAPES) for the Ph.D scholarship awarded to Roberta Marques, for financial support in the "sandwich" program (Process: 47/2017), and for grants awarded to the second and third authors (CAPES grant numbers 88882.306693/2018-01 and 88882.182253/2018-01, respectively).

Conflicts of Interest: The authors declare no conflict of interest.

\section{References}

1. Vilkamaa, P. Checklist of the family Sciaridae (Diptera) of Finland. Zookeys 2014, 441, 151-164. [CrossRef]

2. Han, Q.X.; Cheng, D.M.; Luo, J.; Zhou, C.Z.; Lin, Q.S.; Xiang, M.M. First report of Bradysia difformis (Diptera: Sciaridae) damage to Phalaenopsis orchid in China. J. Asia-Pac. Entomol. 2015, 18, 77-81. [CrossRef]

3. Mohrig, W.; Heller, K.; Hippa, H.; Vilkamaa, P.; Menzel, F. Revision of black fungus gnats (Diptera: Sciaridae) of North America. Studia Dipterol. 2013, 19, 141-286.

4. Shin, S.-G.; Lee, H.-S.; Lee, S. Dark winged fungus gnats (Diptera: Sciaridae) collected from shiitake mushroom in Korea. J. Asia-Pac. Entomol. 2012, 15, 174-181. [CrossRef]

5. Ye, L.; Leng, R.; Huang, J.; Qu, C.; Wu, H. Review of three black fungus gnat species (Diptera: Sciaridae) from greenhouses in China: Three greenhouse sciarids from China. J. Asia-Pac. Entomol. 2017, 20, 179-184. [CrossRef]

6. Shamshad, A. The development of integrated pest management for the control of mushroom sciarid flies, Lycoriella ingenua (Dufour) and Bradysia ocellaris (Comstock), in cultivated mushrooms. Pest Manag. Sci. 2010, 66, 1063-1074. [CrossRef]

7. Grimm, D.; Wösten, H.A.B. Mushroom cultivation in the circular economy. Appl. Microbiol. Biotechnol. 2018, 102, 7795-7803. [CrossRef]

8. Royse, D.J.; Baars, J.; Tan, Q. Current overview of mushroom production in the world. In Edible and Medicinal Mushrooms; Diego, C.Z., Pardo-Giménez, A., Eds.; John Wiley \& Sons, Ltd.: Chichester, UK, 2017; pp. 5-13. [CrossRef]

9. National Agricultural Statistics Service (USDA), Agricultural Statistics Board. Mushrooms. Washington, DC, USA, 2020. Available online: https://www.nass.usda.gov/Statistics_by_State/Wisconsin/Publications/Crops/2020/US-Mushrooms-08 -20.pdf (accessed on 13 February 2021). 
10. Lewandowski, M.; Sznyk, A.; Bednarek, A. Biology and morphometry of Lycoriella ingenua (Diptera: Sciaridae). Biol. Lett. 2004, 41, 41-50.

11. Yi, J.-H.; Park, I.-K.; Choi, K.-S.; Shin, S.-C.; Ahn, Y.-J. Toxicity of medicinal plant extracts to Lycoriella ingenua (Diptera: Sciaridae) and Coboldia fuscipes (Diptera: Scatopsidae). J. Asia-Pac. Entomol. 2008, 11, 221-223. [CrossRef]

12. Rinker, D.L. Insect, mite, and nematode pests of commercial mushroom production. In Edible and Medicinal Mushrooms; Zied, C., Pardo-Giménez, A., Eds.; John Wiley \& Sons, Ltd.: Hoboken, NJ, USA, 2017; pp. 221-237. [CrossRef]

13. Cloyd, R.A.; Zaborski, E.R. Fungus gnats, Bradysia spp. (Diptera: Sciaridae), and other arthropods in commercial bagged soilless growing media and rooted plant plugs. J. Econ. Entomol. 2004, 97, 503-510. [CrossRef] [PubMed]

14. Hulme, P.E. Trade, transport and trouble: Managing invasive species pathways in an era of globalization. J. Appl. Ecol. 2009, 46, 10-18. [CrossRef]

15. Peterson, A.; Soberón, J.; Pearson, R.G.; Anderson, R.; Martínez-Meyer, E.; Nakamura, M.; Araújo, M. Ecological Niches and Geographic Distributions; Princeton University Press: Princeton, NJ, USA, 2011.

16. Compton, T.J.; Leathwick, J.R.; Inglis, G.J. Thermogeography predicts the potential global range of the invasive European green crab (Carcinus maenas). Divers. Distrib. 2010, 16, 243-255. [CrossRef]

17. Gallien, L.; Münkemüller, T.; Albert, C.H.; Boulangeat, I.; Thuiller, W. Predicting potential distributions of invasive species: Where to go from here? Divers. Distrib. 2010, 16, 331-342. [CrossRef]

18. Thuiller, W.; Richardson, D.M.; Pyšek, P.; Midgley, G.F.; Hughes, G.O.; Rouget, M. Niche-based modelling as a tool for predicting the risk of alien plant invasions at a global scale. Glob. Chang. Biol. 2005, 11, 2234-2250. [CrossRef]

19. Papp, L.; Darvas, B. 'Contributions to a Manual of Palaearctic Diptera.' (Science Herald). Available online: https://agris.fao.org/ agris-search/search.do?recordID=US201300058453 (accessed on 3 March 2021).

20. GBIF. Download Lycoriella agraria Occurrences. 2020. Available online: https://doi.org/10.15468/dl.hrntwd (accessed on 15 November 2020).

21. GBIF. Download Sciara multiseta Occurrences. 2020. Available online: https://doi.org/10.15468/dl.e6qf9b (accessed on 15 November 2020).

22. GBIF. Download Lycoriella ingenua Occurrences. 2020. Available online: https://doi.org/10.15468/dl.7y5g8w (accessed on 15 November 2020).

23. GBIF. Download Sciara pauciseta Occurrences. 2020. Available online: https://doi.org/10.15468/dl.uhk2m4 (accessed on 15 November 2020).

24. GBIF. Download Lycoriella sativae Occurrences. 2020. Available online: https://doi.org/10.15468/dl.qdcafo (accessed on 15 November 2020).

25. GBIF. Download Lycoriella auripila Occurrences. 2020. Available online: https://doi.org/10.15468/dl.yjtvtr (accessed on 15 November 2020).

26. GBIF. Download Lycoriella castanescens Occurrences. 2020. Available online: https://doi.org/10.15468/dl.yobjuj (accessed on 15 November 2020).

27. Aiello-Lammens, M.E.; Boria, R.A.; Radosavljevic, A.; Vilela, B.; Anderson, R.P. spThin: An R package for spatial thinning of species occurrence records for use in ecological niche models. Ecography 2015, 38, 541-545. [CrossRef]

28. Hijmans, R.J.; Cameron, S.E.; Parra, J.L.; Jones, P.G.; Jarvis, A. Very high resolution interpolated climate surfaces for global land areas. Int. J. Climatol. 2005, 25, 1965-1978. [CrossRef]

29. Escobar, L.E.; Lira-Noriega, A.; Medina-Vogel, G.; Peterson, A.T. Potential for spread of the white-nose fungus (Pseudogymnoascus destructans) in the Americas: Use of Maxent and NicheA to assure strict model transference. Geospat. Health 2014, 9, 221-229. [CrossRef]

30. CCAFS. GCM Downscaled Data Portal—Spatial Downscaling Data. 2020. Available online: http://www.ccafs-climate.org/data spatial_downscaling/ (accessed on 15 January 2021).

31. Cobos, M.E.; Peterson, A.T.; Osorio-Olvera, L.; Jiménez-García, D. An exhaustive analysis of heuristic methods for variable selection in ecological niche modeling and species distribution modeling. Ecol. Inform. 2019, 53, 100983. [CrossRef]

32. Phillips, S.J.; Dudík, M.; Schapire, R.E. A Maximum Entropy Approach to Species Distribution Modeling. In Proceedings of the Twenty-First International Conference on Machine Learning-ICML '04, Banff, AB, Canada, 4-8 July 2004; ACM Press: New York, NY, USA, 2004; p. 83.

33. Cobos, M.E.; Peterson, A.T.; Barve, N.; Osorio-Olvera, L. kuenm: An R package for detailed development of ecological niche models using Maxent. PeerJ 2019, 7, e6281. [CrossRef]

34. Peterson, A.T.; Papeş, M.; Soberón, J. Rethinking receiver operating characteristic analysis applications in ecological niche modeling. Ecol. Model. 2008, 213, 63-72. [CrossRef]

35. Warren, D.L.; Seifert, S.N. Ecological niche modeling in Maxent: The importance of model complexity and the performance of model selection criteria. Ecol. Appl. 2011, 21, 335-342. [CrossRef] [PubMed]

36. Anderson, R.P.; Raza, A. The effect of the extent of the study region on GIS models of species geographic distributions and estimates of niche evolution: Preliminary tests with montane rodents (genus Nephelomys) in Venezuela. J. Biogeogr. 2010, 37, 1378-1393. [CrossRef] 
37. Barve, N.; Barve, V.; Jiménez-Valverde, A.; Lira-Noriega, A.; Maher, S.P.; Peterson, A.T.; Soberón, J.; Villalobos, F. The crucial role of the accessible area in ecological niche modeling and species distribution modeling. Ecol. Model. 2011, 222, 1810-1819. [CrossRef]

38. Owens, H.L.; Campbell, L.P.; Dornak, L.L.; Saupe, E.E.; Barve, N.; Soberón, J.; Ingenloff, K.; Lira-Noriega, A.; Hensz, C.M.; Myers, C.E.; et al. Constraints on interpretation of ecological niche models by limited environmental ranges on calibration areas. Ecol. Model. 2013, 263, 10-18. [CrossRef]

39. Osorio-Olvera, L.; Lira-Noriega, A.; Soberón, J.; Peterson, A.T.; Falconi, M.; Contreras-Díaz, R.G.; Martínez-Meyer, E.; Barve, V.; Barve, N. ntbox: An R package with graphical user interface for modelling and evaluating multidimensional ecological niches. Methods Ecol. Evol. 2020, 11, 1199-1206. [CrossRef]

40. IPCC. Climate Change 2014: Synthesis Report. Intergovernmental Panel on Climate Change, (New York, NY, USA). 2014. Available online: https://www.ipcc.ch/pdf/assessment-3report/ar5/syr/AR5_SYR_FINAL_SPM.pdf (accessed on 15 February 2020).

41. Sawangproh, W.; Ekroos, J.; Cronberg, N. The effect of ambient temperature on larvae of Scatopsciara cunicularius (Diptera: Sciaridae) feeding on the thallose liverwort Marchantia polymorpha. Eur. J. Entomol. 2016, 113, 259-264. [CrossRef]

42. Chidziya, E.; Mutangadura, D.; Jere, J.; Siziba, L. A comparative evaluation of locally available substrates for rearing and studying biology of sciarid fly, Lycoriella mali. Acad. J. Biotechnol. 2013, 1, 57-61.

43. Katumanyane, A.; Kanzi, A.M.; Malan, A.R. Sciarid pests (Diptera: Sciaridae) from undercover crop production in South Africa. S. Afr. J. Sci. 2020, 116, 1-6. [CrossRef]

44. Gaitán-Hernández, R. Uso del Sustrato Residual del Cultivo de Pleurotus spp. 'Sánchez JE and Royse DJ. La Biología, el Cultivo y las Propiedades Nutricionales y Medicinales de las Setas Pleurotus spp.'; El Colegio de la Frontera Sur: Tapachula, México, 2017; pp. 261-282.

45. Duarte, J.L.P.; da Fonseca Duarte, A.; da Cunha, U.S. A new threat for mushroom growers in South America: First record of Coboldia fuscipes (Meigen, 1830) (Diptera, Scatopsidae) massive damage to Pleurotus spp. Int. J. Trop. Insect Sci. 2020, 41, 887-890. [CrossRef]

46. Menzel, F.; Smith, J.E.; Colauto, N.B. Bradysia difformis Frey and Bradysia ocellaris (Comstock): Two additional Neotropical species of black fungus gnats (Diptera: Sciaridae) of economic importance: A redescription and review. Ann. Entomol. Soc. Am. 2003, 96, 448-457. [CrossRef]

47. Broadley, A.; Kauschke, E.; Mohrig, W. Black fungus gnats (Diptera: Sciaridae) found in association with cultivated plants and mushrooms in Australia, with notes on cosmopolitan pest species and biosecurity interceptions. Zootaxa 2018, 4415, $201-242$. [CrossRef] [PubMed]

48. Jess, S.; Schweizer, H. Biological control of Lycoriella ingenua (Diptera: Sciaridae) in commercial mushroom (Agaricus bisporus) cultivation: A comparison between Hypoaspis miles and Steinernema feltiae. Pest Manag. Sci. 2009, 65, 1195-1200. [CrossRef] [PubMed] 